\title{
Effect of land cover on air temperatures involved in the development of an intra-urban heat island
}

\author{
Takuya Yokobori, Shunji Ohta*
}

Faculty of Human Sciences, Waseda University, Mikajima 2-579-15, Tokorozawa, Saitama 359-1192, Japan

\begin{abstract}
Mobile traverses were used to conduct air temperature observations to clarify the effect of land cover on ambient air temperatures. The study area was located in a suburb of the Tokyo metropolitan area, Japan. The mobile traverses were conducted at $2 \mathrm{~h}$ intervals between 10:00 $\mathrm{h}$ on one day and 08:00 h the next day, on selected days from October 2006 to March 2008, for a total of $30 \mathrm{~d}$. We observed an intra-urban heat island (IUHI) throughout the year and determined the diurnal and seasonal variations in this IUHI. The daily maximum intensities of the IUHI under calm and cloudless conditions ranged from 4.0 to $6.9^{\circ} \mathrm{C}$ during all seasons of the years examined. Such large IUHI intensities are determined by clear boundaries between adjacent land covers, independent of a city's size. The development of an IUHI is related to the features of the land cover, and the causal factors that enhance an IUHI differ between day- and nighttime. In most cases, observed air temperatures varied significantly according to ambient land cover types, and air temperatures decreased as the amount of vegetated area around the sites increased. These land cover effects were slightly stronger at night than during the day, and they weakened as the amount of cloud cover or the wind speed increased, especially at night.
\end{abstract}

KEY WORDS: Urban heat island $\cdot$ Air temperature $\cdot$ Mobile traverse $\cdot$ Land cover $\cdot$ Vegetation Urban climate $\cdot$ Weather condition

\section{INTRODUCTION}

Urban climate is influenced by many factors related to the intrinsic nature of a city, such as its size, building density and land use distribution, and is affected by external influences such as the surrounding climate and prevailing weather and seasons (Oke 1982). In particular, the causal factors are brought about by land use alterations in the process of urbanization because land use alterations can expand a city and replace vegetated and open areas with buildings and paved roads. Because of rapid progression of these processes in the metropolitan area in Tokyo, Japan, air temperatures are rising at a faster rate than global warming (Ooka 2007). The urban area increases the absorption and storage of incoming solar radiation because the canyon geometry of an urban area increases the surface area and leads to multiple reflections (Oke 1982). The urban canyon geometry regulates long-wave radiation heat loss due to a reduction in the sky view factor (Oke 1981,
1982, Erell \& Williamson 2007). The characteristics of urban surfaces can result in a reduction of evapotranspiration (Oke 1982). In addition, urban areas are sources of anthropogenic heat (Oke 1982, Ichinose et al. 1999, Sailor \& Lu 2004). As a result, the energy balance in an urban area is disturbed. This effect of the urban climate on air temperatures is called urban heat island (UHI), which refers to the temperature difference between urban areas and surrounding cool rural areas.

Vegetation can play an important role in moderating this phenomenon, because the incoming radiation energy in a vegetated area is converted into latent heat during the day and the sensible heat flux is lower than that of a built-up area covered by asphalt or concrete (Wilmers 1991, Jonsson 2004). In addition, the greater shading of trees or the reflection from vegetation reduces the radiant absorption of the ground (Oke 1987). At night, a vegetated area with short plants or an area of open bare ground may cool rapidly due to its higher radiative cooling rate (Spronken-Smith \& Oke 
1999), whereas a built-up area with a relatively low sky view factor may cool more slowly (Oke 1981).

Many field studies have demonstrated the features of UHIs and the effects of vegetated areas on local climate (Saito et al. 1991, Eliasson 1996a, Upmanis \& Chen 1999, Unger et al. 2001, Jonsson 2004, Bottyán et al. 2005, Hart \& Sailor 2009). Saito et al. (1991) reported that abundant vegetated land cover decreases ambient air temperature. During summer, this decrease in temperature due to green coverage occurs independently of the time of day. Unger et al. (2001) and Bottyán et al. (2005) showed a similar relationship between vegetated land cover and air temperatures on the basis of seasonal observations made $4 \mathrm{~h}$ after sunset. In addition, Hart \& Sailor (2009) quantified the influence of land use and surface characteristics, which also indicated the existence of lower temperatures in parks and green spaces.

Many studies have indicated the usefulness of vegetation for improving the thermal environment in an urban area. However, these results were obtained from observations conducted throughout the day using a few fixed meteorological stations or, less frequently, from spatial observations using mobile traverses. To understand the influence of land cover on urban climate, detailed measurements must be taken. The present study was carried out in a city located approximately $30 \mathrm{~km}$ from the Tokyo metropolis. The study area is not a large city; rather, it is comprised of a typical built-up urban area and a rural vegetated area, which makes it suitable to demonstrate the effect of land cover on air temperatures. To investigate the effect of land cover on air temperatures, many measurement sites must be established in the study area, because the existing meteorological stations are too sparse to obtain a detailed air temperature structure (Yamashita 1996). Eliasson (1996a) mentioned that mobile traverses enable the easy establishment of observation points along a measurement route. However, since such investigations require considerable effort, previous studies were performed only over a short period or for a specific time. Therefore, it has been difficult to understand the timing of the appearance of maximum UHI intensity. In the present study, we used mobile traverses and set measurement sites across different major types of land cover to study the effect of land cover types and of the amount of vegetated area around the sites. We conducted these measurements during the day and at night throughout the year under different weather conditions.

The present study primarily aimed to reveal the timing of the appearance of the maximum air temperature differences diurnally and seasonally and to examine the effect of land cover on the development of air temperature differences. Although many factors contri- bute to air temperature differences, we only focused on land cover. This is an essential first step to understand air temperature differences in the study area, because land cover directly affects the energy balance characteristics.

This study was conducted as follows. (1) We investigated diurnal and seasonal variations in air temperature difference throughout the year by using mobile traverses, and compared the air temperatures observed in different land cover types. (2) We set up measurement sites in urban cross sections to transect major types of land cover, and performed measurements under different weather conditions to clarify the moderating effect of vegetated areas on ambient air temperatures. (3) To elucidate the conditions that can play a key role in enhancing the effect, we analyzed the influence of weather conditions on the magnitude of the moderating effect.

\section{METHODS}

\subsection{Study area and climate}

The study area (latitude: $35^{\circ} 48^{\prime} \mathrm{N}$, longitude: $139^{\circ} 25^{\prime} \mathrm{E}$ ) is located in a suburb of the Tokyo metropolitan area, Kanto Plain, Japan, at approximately $80 \mathrm{~m}$ above sea level. The area is approximately $30 \mathrm{~km}$ from downtown Tokyo, and is considered a typical suburb in the area spreading concentrically from the Tokyo metropolis. The study area has a population of approximately 40000 and a population density of 4000 people per square kilometer. At a nearby fixed weather station of the Automated Meteorological Data Acquisition System (AMeDAS) in Tokorozawa, the annual mean temperature measured is $14.1^{\circ} \mathrm{C}$ and the annual precipitation is $1443.9 \mathrm{~mm}$, which is concentrated during the warmer half of the year. Generally, the summer is hot and humid (the average temperature in August is $25.5^{\circ} \mathrm{C}$ ), and the winter is cold and dry (the average temperature in January is $3.6^{\circ} \mathrm{C}$ ). The wind speeds are relatively weak, with monthly means ranging between 1.7 and $2.7 \mathrm{~m} \mathrm{~s}^{-1}$.

\subsection{Measurement sites}

There were 40 measurement sites across this area of the city, which is composed of various land cover types, such as secondary woodland, cropland mainly used for green tea plantations, and a built-up area (Fig. 1). The secondary woodland, which covers a widespread area, is a distinct type of land use because it consists of an assemblage of trees that would not naturally exist without human intervention. The cropland consists of short vegetation. The built-up area consists mainly of 2 to 3 story 
a

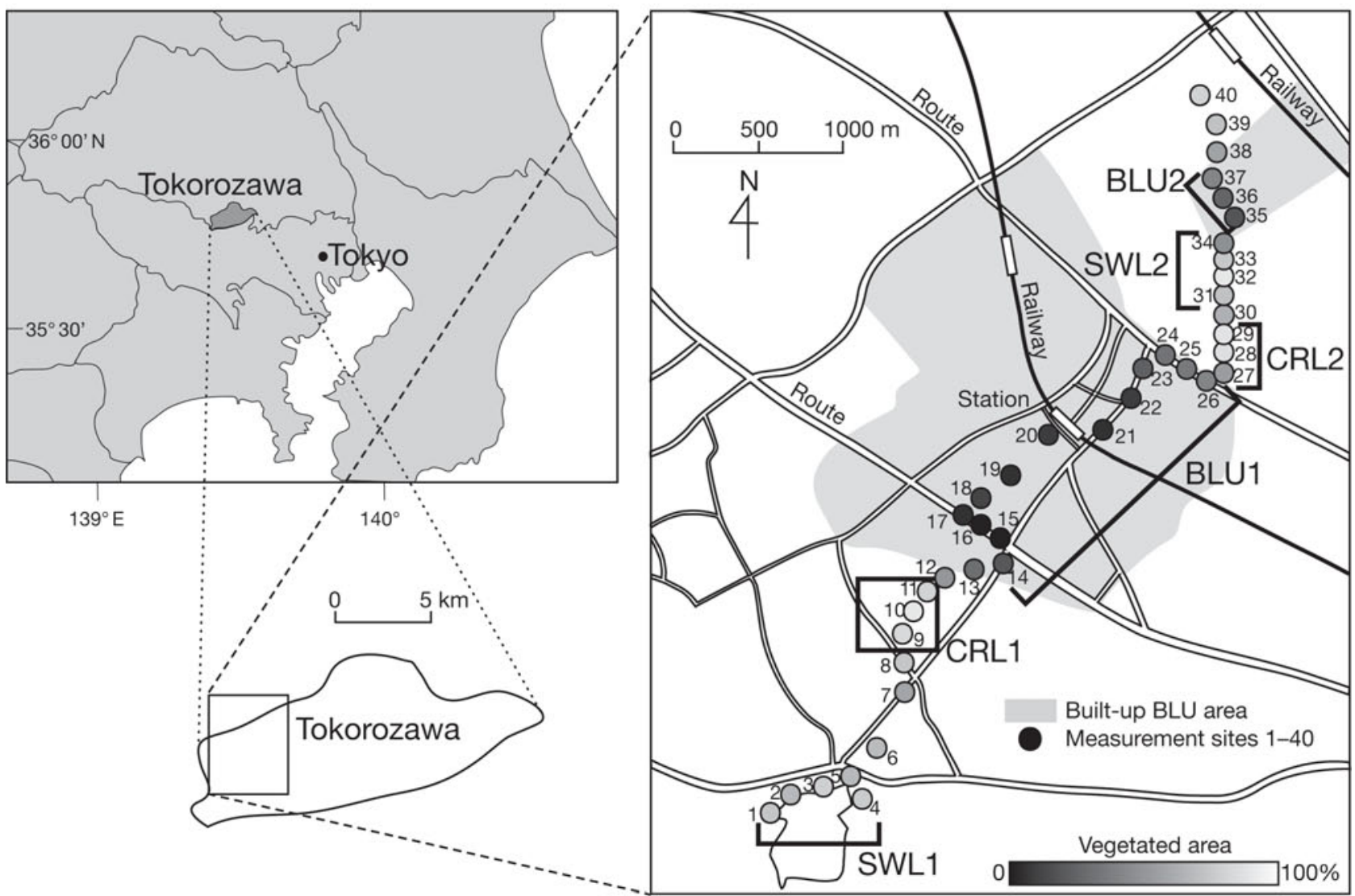

b

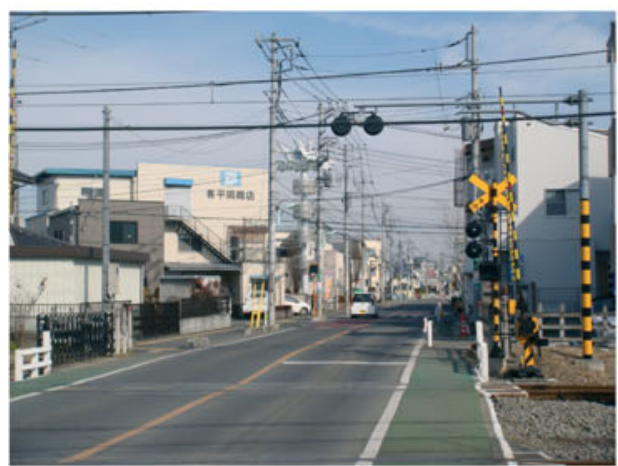

d

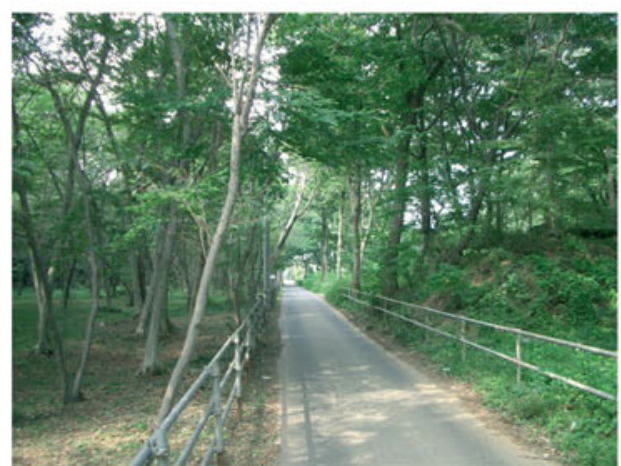

C

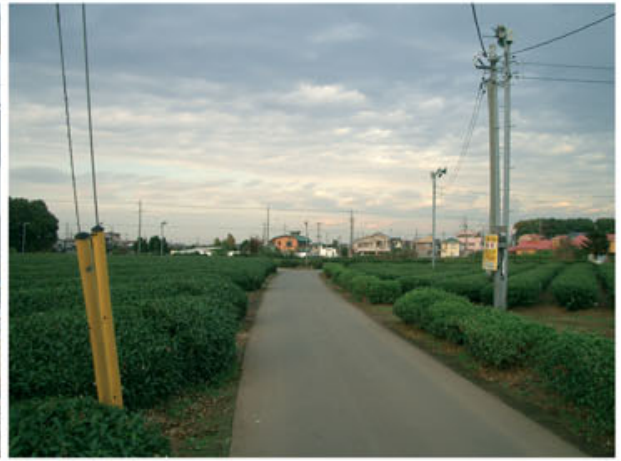

e

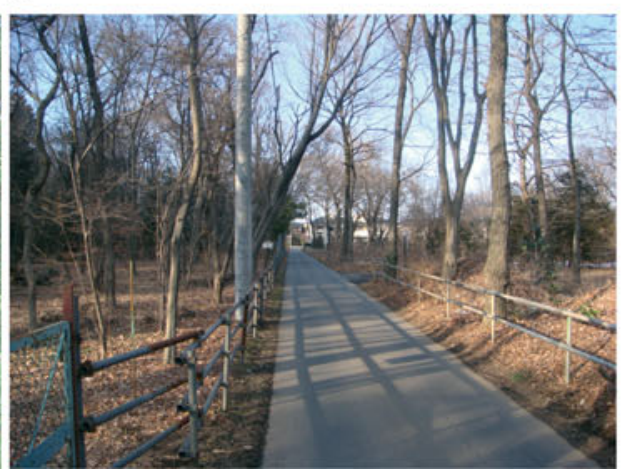

Fig. 1. (a) Geographic features of the study area and (b-e) photographs of land use characteristics in (b) the built-up area for Site 21, (c) the cropland of Site 10 and (d) the secondary woodland of Site 33 in summer and (e) in winter. Locations of observation sites are indicated by grayscale circles; the grayscale represents the percentages of vegetated area within an area of $90000 \mathrm{~m}^{2}$ surrounded by a 300 $\mathrm{m}$ buffer zone at each measurement site. The observation transect is composed of various land cover types, such as cropland (CRL1 and 2), secondary woodland (SWL1 and $2)$, and built-up areas (BLU1 and 2). The extent of BLU1 and 2 in the study area is highlighted in gray 
residences. Mobile traverses were used to measure the air temperature at these sites by rotation. The length of a transect observation strip was approximately $5 \mathrm{~km}$; each site was located at intervals of approximately 100 to $400 \mathrm{~m}$. The characteristics of this study area, consisting of various land cover types within a limited area, are ideal for urban climate investigations. As a result, we could efficiently perform measurements of the spatial structure of the UHI by using mobile traverses. These investigations would be difficult to achieve with stationary measurements because of the lack of space for installations and the expense involved. However, since the observation sites were limited to several square kilometers and to avoid a debate over whether this area was large enough to properly assess the characteristics of a UHI, we use the term intra-urban heat island (IUHI) to describe the temperature differences between the different sites in the present study, as in the case of Erell \& Williamson (2007).

\subsection{Observation times}

Mobile traverses were used to conduct air temperature measurements at $2 \mathrm{~h}$ intervals between 10:00 $\mathrm{h}$ on one day and 08:00 $\mathrm{h}$ the next day, on selected days from October 2006 to March 2008, for a total of $30 \mathrm{~d}$ under all weather conditions. Because of some missing data, a total of 327 traverses were obtained. The distribution of measurement values according to season and weather conditions are shown in Table 1. Instead of using an automobile, as is normally the case, we used a motorbike for the moving observations in our study. Using a motorbike enabled greater flexibility in arranging the observation route and mobility for conducting mobile traverses. Due to this efficient mobile
Table 1. Seasonal distribution of measurements (n) according to time of day and weather conditions

\begin{tabular}{|lccccc|}
\hline & Spring & Summer & Autumn & Winter & Total \\
\hline Diel period & & & & & \\
Day & 38 & 49 & 44 & 30 & 161 \\
Night & 31 & 35 & 47 & 53 & 166 \\
Total & 69 & 84 & 91 & 83 & 327 \\
Weather conditions & & & & \\
Cloud cover & 39 & 41 & 54 & 64 & 198 \\
$\quad 0-60 \%$ & 28 & 41 & 27 & 15 & 111 \\
$70-100 \%$ & 2 & 2 & 10 & 4 & 18 \\
Rain & 2 & & & & \\
\hline
\end{tabular}

measurement method, we performed a large number of measurements during the course of $1 \mathrm{~d}$. Since each mobile traverse required approximately $20 \mathrm{~min}$, we did not correct the series of observed temperatures for time-lag control.

\subsection{Instruments and data acquisition}

A radiation-shielded thermistor temperature sensor (resolution $0.1^{\circ} \mathrm{C}$ ) connected to a portable TR-52 data logger (T\&D) for digital sampling (Fig. 2) was used to obtain the temperature readings. Two vinyl chloride tubes of different sizes - lengths, diameters, and thicknesses of 250/80/3 mm and 230/55/2 mm - were used to construct the radiation shield; the smaller tube was installed within the larger one. Both ends of these tubes were left open for ventilation. The outside of the larger tube was coated with a silver-colored film to prevent solar radiation from causing measurement errors. In addition, to diminish diffuse reflection inside
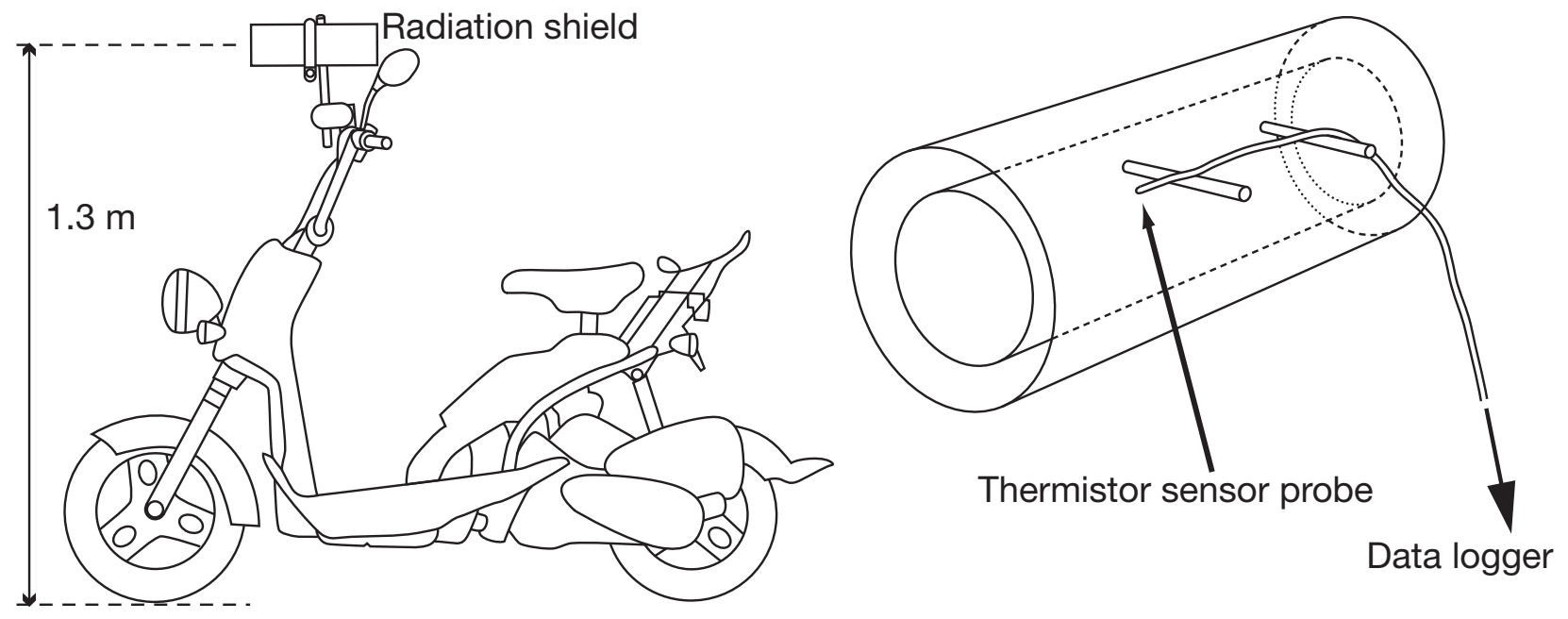

Fig. 2. Thermistor sensor probe and radiation shield mounted on the observation motorbike 
the radiation shield, the inside of the larger tube and both sides of the smaller tube were painted black. The thermistor temperature sensor was set in the central part inside the radiation shield. The radiation-shielded thermistor temperature sensor was mounted on the motorbike at a height of $1.3 \mathrm{~m}$ above the ground (Fig. 2).

The air temperature data were collected continuously every second during the traverses, and we transited the measurement sites logging the transit times; we did not stop at the measurement sites. The motorbike was driven at a constant speed of 20 to $30 \mathrm{~km} \mathrm{~h}^{-1}$, which was sufficient to provide adequate ventilation to allow the sensor to measure the instantaneous ambient air temperature. The split-time feature of a stopwatch was used to log the transit time for each measurement site, and the recorded value was related to its measurement site along the measurement route. After completing the traverses, we averaged the data for every $5 \mathrm{~s}$ to minimize the observation errors and extracted the air temperature data around each site before further analysis.

To observe temperatures under the same conditions, we conducted all of the traverses in the same direction, from Site 1 to Site 40. However, performing them alternately in opposite directions could have reduced any possible bias.

\subsection{Land cover classification}

Aerial photographs (Google Maps, http://maps. google.com/, accessed 3 June, 2008) were used to classify the land cover conditions in the study area. We regarded the dominant land cover type within each grid as its land cover condition. The photographs of the study area, containing all measurement sites, were divided into $10 \mathrm{~m}$ square grids, and the land cover conditions in each grid were determined. The spatial resolution of the aerial photographs was sufficient to deter- mine land cover conditions by visual judgment alone. In addition, we were able to classify land cover conditions ourselves. For instance, the vegetation existing within the residential area is not classified as vegetation in GIS data, such as with the Detailed Digital Information (10 m Grid Land Use-GIS). However, there is much vegetation in the gardens or along the road in our study area.

Land cover conditions were classified into 5 categories: buildings, roads and parking space, cropland, secondary woodland, and bare ground. Relatively tall trees were classified as secondary woodland and relatively short trees were classified as cropland. Bare ground contained playgrounds and athletic fields, such as at schools. Since the differences in building height in our study area were small, we did not classify the buildings according to their height. Although the amount of vegetated area actually varies seasonally, we did not consider seasonal changes in the vegetated area because these were not visible in the aerial photographs. In addition, since the available images were probably taken in winter, more areas were classified as bare ground than are actually bare ground through most of the year.

The study area was square so we were able to construct a database using grid data. Because Yokohari et al. (2001) reported that the cooling effect of different land cover types reaches a steady temperature at approximately $150 \mathrm{~m}$ into the neighborhood, the surveyed area around each site was $90000 \mathrm{~m}^{2}$ in size and surrounded by a $300 \mathrm{~m}$ buffer zone, as in the case of Hart \& Sailor (2009). Fig. 3a indicates the percentages of each land cover condition within $90000 \mathrm{~m}^{2}$ around each of the 40 sites. Buildings, roads, and parking spaces, i.e. artificial land cover, occupied $50.8 \%$ of the entire study area. The other land cover condition, vegetated land cover and natural land cover, occupied $49.2 \%$. Fig. 3b shows the percentages of each land
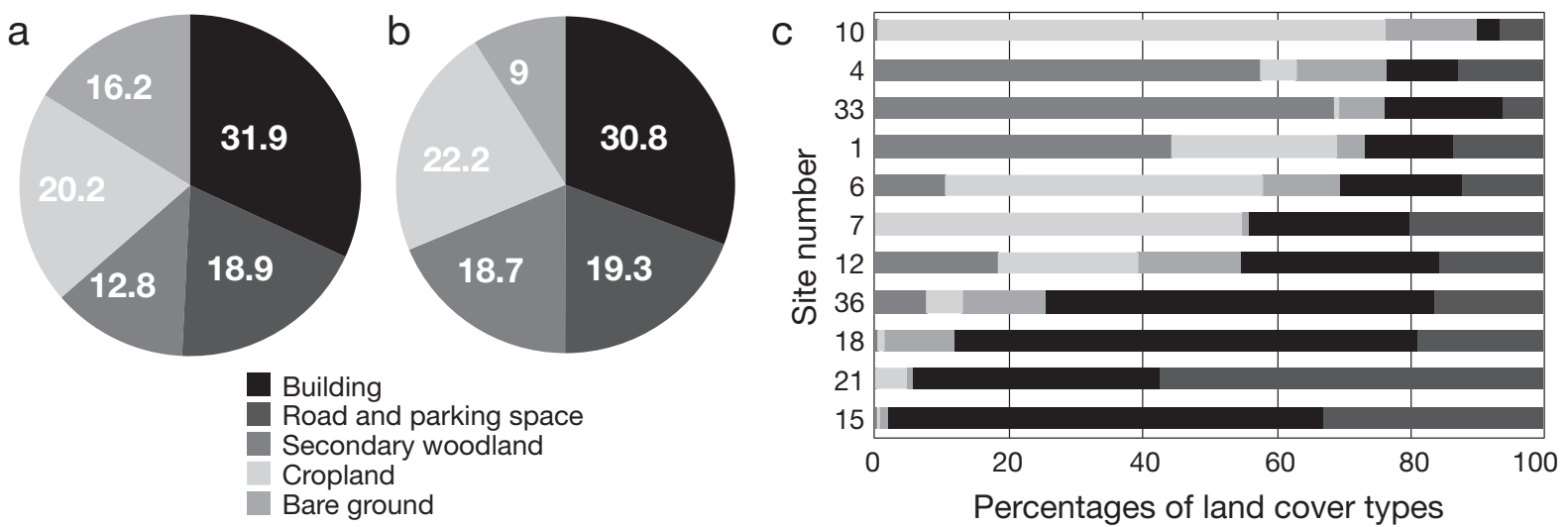

Fig. 3. Percentages of different land cover conditions at (a) all sites $(n=40)$, (b) 11 representative sites combined, and (c) at each of the 11 representative sites 
cover class around 11 representative sites (Sites 1, 4, 6, $7,10,12,15,18,21,33$, and 36). These sites were selected for analyses because they were located approximately in the center of a single dominant land cover type. We excluded sites that contained several different land cover types or that may have been affected by them. For instance, a site that had a high percent of vegetation but was located right next to some buildings was excluded. To avoid double counting within the same land cover grid, we did not use all sites for the analyses, although we have land cover and air temperature data for all of them, because sites were located at intervals of about 100 to $400 \mathrm{~m}$ (which could make the sum of the land cover data greater than $100 \%$ ). Therefore, we used the area of land cover around the sites to avoid duplication. Of these areas, 50.1\% was artificial land cover and $49.9 \%$ was vegetated and natural land cover. Fig. 3c shows the percentages of each land cover condition within an area of $90000 \mathrm{~m}^{2}$ enclosed by $300 \mathrm{~m}$ sides around each of the 11 representative sites. Most of the areas around Sites 15, 21, 18, and 36 were classified as artificial land cover. This made up 73 to $98 \%$ of these areas. The areas around the other 7 sites were dominated by vegetated and natural land cover. Of these areas, 55 to $90 \%$ had no artificial land cover.

The sky view factor at the secondary woodland and cropland sites was 0.60 and 0.85 , respectively. These values are comparable to those from the urban area ( 0.60 to 0.73 ) because the city core of the study area mainly consists of approximately 2 to 3 story residences. Therefore, we focused on the land cover data rather than the sky view factor values to try to explain the air temperature differences, although the sky view factor is one of the most important factors causing a UHI.

\section{RESULTS}

\subsection{Diurnal and seasonal variations in intra-urban heat island intensity}

Of the $30 \mathrm{~d}$ on which observations were made, 11 were almost calm and cloudless; such weather conditions are the most suitable for the development of IUHIs. We selected 4 of these $11 \mathrm{~d}$ to represent the conditions during the 4 seasons. For example, a representative summer day was selected based on the hottest conditions with calm and cloudless weather. Likewise, the representative winter day was selected based on the coldest conditions with calm and cloudless weather. Typical examples of the diurnal changes in the IUHI intensity according to the seasons observed during these $4 \mathrm{~d}$ are shown in Fig. 4 . In spring and winter, the maximum IUHI intensity occurred from midnight to before sunrise. In autumn, the IUHI intensities reached their maximum within a few hours after sunset and then declined gradually throughout the remainder of the night. Compared to other seasons, the IUHI intensities in summer increased to a greater extent during the day than at night. Fig. 4 shows that the diurnal variations of the IUHI intensity differed significantly within a given season. In the present study, daily maximum IUHI intensities under calm and cloudless weather conditions ranged from 4.0 to $6.9^{\circ} \mathrm{C}$ during all seasons in the years studied.

\subsection{Seasonal air temperature variations in the built-up, cropland, and secondary woodland areas}

The diurnal variations according to the seasons in air temperature in the built-up area (Site 21), the cropland

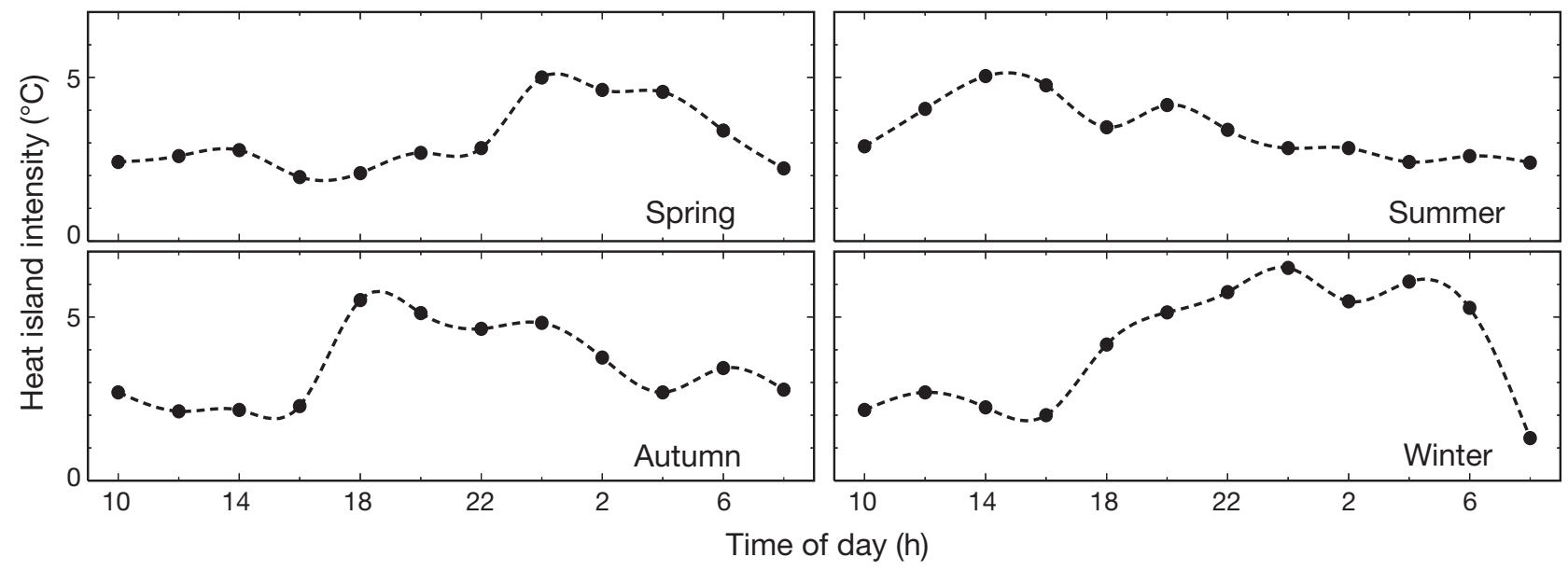

Fig. 4. Diurnal changes in the IUHI intensity under calm and cloudless weather conditions in each season (spring: 28-29 April 2007; summer: 28-29 July 2007; autumn: 19-20 October 2006; winter: 8-9 March 2008). The IUHI intensities were represented by the air temperature differences between the maximum and minimum measured at 40 sites 
area (Site 10), and the secondary woodland area (Site 33) under calm and cloudless weather conditions are shown in Fig. 5. This illustrates the differences in the air temperatures observed in each land cover type. These 3 sites were selected from the 11 representative sites mentioned above because they were located approximately in the central part of each land cover area and were each surrounded by a dominant land cover type. There were air temperature differences among the sites in all seasons, and the magnitudes of these varied diurnally and seasonally (Fig. 5). At night, the maximum air temperature difference tended to occur between the built-up area and the cropland area in spring, autumn, and winter. However, in summer, there was not much of a difference between the air temperature of the cropland area and the air temperature of the secondary woodland area. During the daytime, the air temperature differences were smaller than those at night, except in summer. Compared to other seasons, air temperature differences during the day in summer between the built-up area and the secondary woodland area tended to become large.

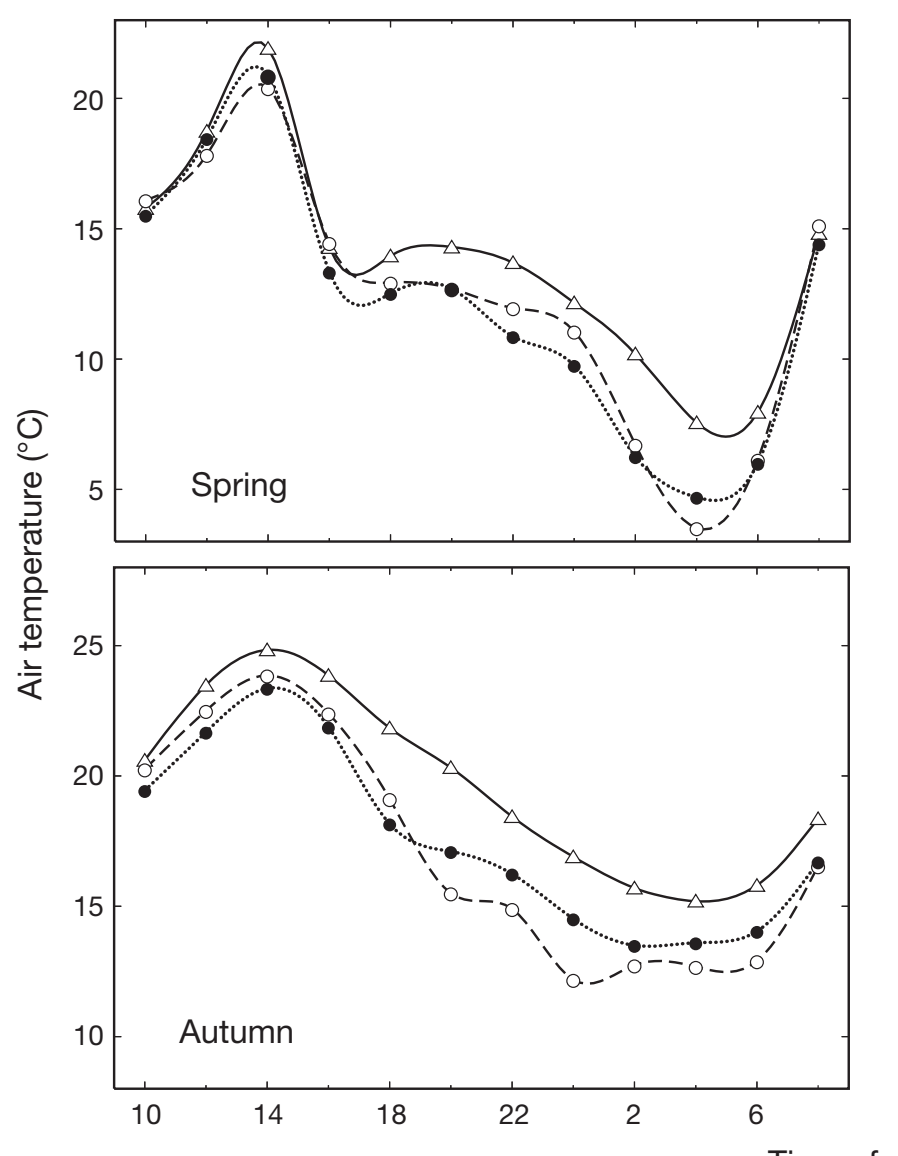

To comprehensively compare the air temperatures observed in different land cover types, we calculated the average temperature at all 40 sites for the same time, along with the temperature deviations from this average value at each of the 3 selected sites. Fig. 6 shows these temperature anomalies in the built-up area (Site 21), the cropland area (Site 10), and the secondary woodland area (Site 33) during the day and at night (8 daytime measurements and 10 nighttime measurements taken in rainy conditions are excluded). The results illustrated in Fig. 6 show greater air temperature differences between the built-up and the vegetated areas at night compared to the daytime. At night, the air temperatures in the built-up area tended to be high throughout the year. In contrast, the air temperatures in the cropland area and the secondary woodland area generally remained low. The maximum air temperature difference tended to appear between the built-up area and the cropland at night during winter and autumn. In addition, air temperature differences in summer were smaller than in other seasons. During the day, the air temperature differences among the land

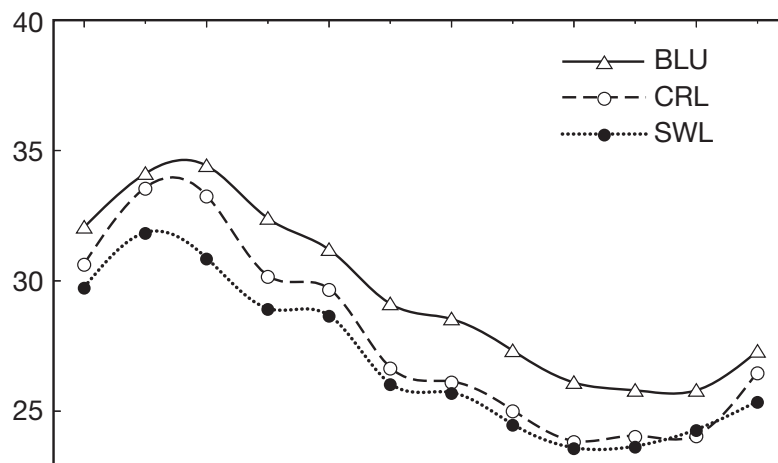

Summer

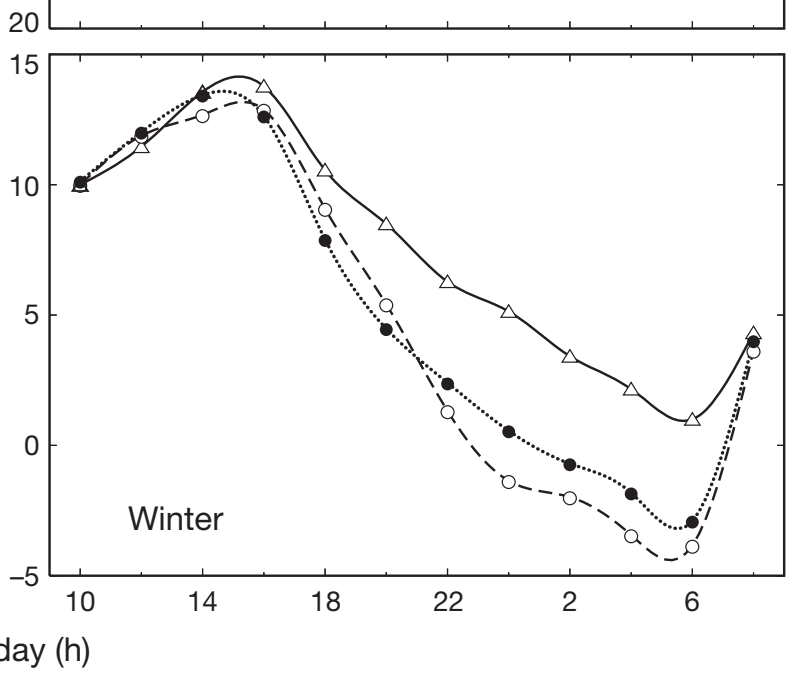

Fig. 5. Diurnal variations in air temperature at the built-up area (BLU, Site 21), the cropland area (CRL, Site 10), and the secondary woodland area (SWL, Site 33) under calm and cloudless weather conditions in each season (spring: 28-29 April 2007; summer: 28-29 July 2007; autumn: 19-20 October 2006; winter: 8-9 March 2008) 

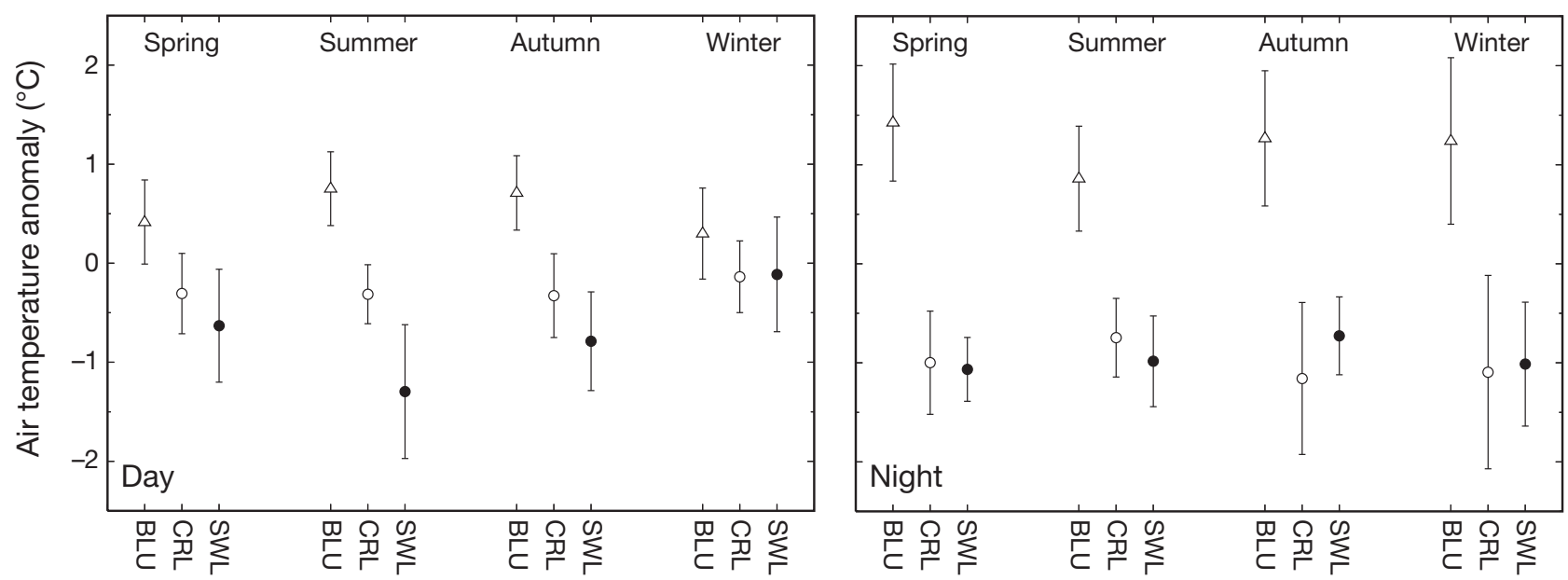

Fig. 6. Air temperature anomalies in each land cover type relative to the transect average of each observation (measurements taken during rainy conditions were excluded). Error bars: \pm SD. Day: sunrise to sunset; night: sunset to sunrise. Abbreviations as in Fig. 5

cover types varied seasonally. These differences were relatively smaller in winter and larger in summer compared to the other seasons. The maximum air temperature difference during the day tended to appear between the built-up area and the secondary woodland area, especially in summer. In total, air temperature anomalies at night were larger than those during the day, except in summer.

\subsection{Influence of percentage vegetated area on air temperatures}

As suggested above, the observed ambient air temperatures varied significantly according to the land cover types. Based on these findings, we used 11 representative sites to analyze the relationship between land cover type and air temperature. These representative sites were, to some extent, separated from each other, and the percentages of land cover types at the sites differed. The percentage of vegetated area and bare ground varied from $2 \%$ at Site 15 to $90 \%$ at Site 10 (Fig. 3c). The analysis is based on the complete dataset, with the exception of 8 daytime measurements and 10 nighttime measurements taken during rainy conditions.

Fig. 7 shows the average day- and nighttime air temperatures for each of the 11 representative sites plotted against the percentage vegetated area. As shown in Fig. 7, both the average day- and nighttime air temper-
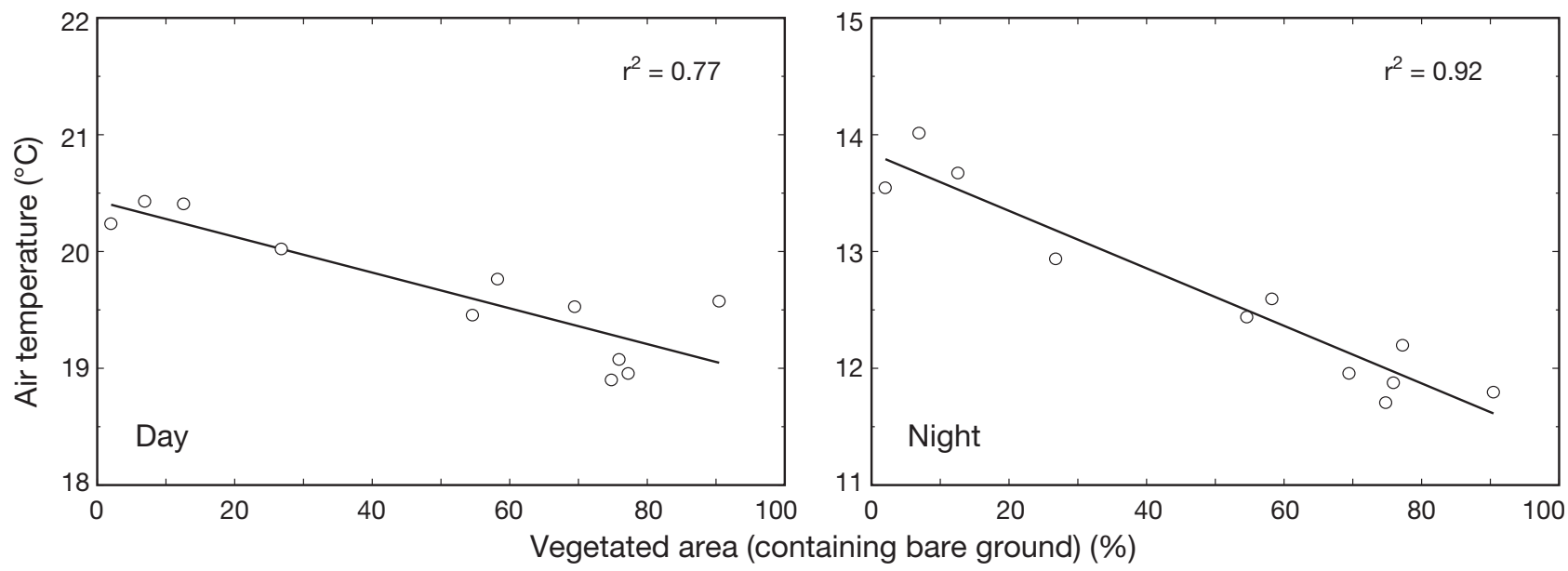

Fig. 7. Relationship between the percentage of vegetated area containing bare ground and the average observed air temperature (excluding measurements taken in rainy conditions). The number of measurements taken at each of the 11 representative sites is $\mathrm{n}=153$ during the day and $\mathrm{n}=156$ at night. Day: sunrise to sunset; night: sunset to sunrise 
atures decreased as the percentage of vegetated area increased. In addition, the magnitude of the decrease in air temperature was greater at night than during the day. The calculated determination coefficients between these 2 factors are $r^{2}=0.77$ during the day and $\mathrm{r}^{2}=0.92$ at night. This indicated a strong $(\mathrm{n}=11)$ relationship between the percentage of vegetated area (plus bare ground) and the average observed air temperature $(\mathrm{p}<0.01)$.

\subsection{Influence of cloud cover or wind speed on air temperature differences}

We examined the influence of weather conditions on the ability of a vegetated area to moderate air temperatures. Cloud cover was documented during the air temperature measurements and wind speeds were obtained from the AMeDAS in Tokorozawa.

Table 2 shows the calculated air temperature differences $(\Delta T a)$ between the temperature in a $0 \%$ vegetated area and that in a $100 \%$ vegetated area according to cloud cover conditions. The linear regression equation and data from the 11 representative sites were used to calculate air temperature differences. This analysis was based on observations of wind speeds of $<3 \mathrm{~m} \mathrm{~s}^{-1}$. As indicated in Table 2, the air temperature differences exhibited significantly different tendencies under clear and rainy sky conditions, both during the day and at the night. In the daytime, the air temperature differences under cloudy sky conditions were not always lower than those under clear sky conditions. On the other hand, the air temperature differ-
Table 2. Calculated day/night air temperature differences, $\Delta T a\left({ }^{\circ} \mathrm{C}\right)$, classified according to weather conditions. Air temperature differences were calculated as the difference between the temperature in a $0 \%$ and that in a $100 \%$ vegetated area using a linear regression on data from the 11 representative sites, as described in Fig. 7. This analysis was based on observations made during wind speeds of $<3 \mathrm{~m} \mathrm{~s}^{-1}$. Day: sunrise to sunset; night: sunset to sunrise; rain: $>0 \mathrm{~mm}$ during the course of observation. Data are mean $\pm \mathrm{SD}$; the number of observation is given in parentheses

\begin{tabular}{|lcc|}
\hline \multicolumn{2}{c|}{ Day } & Night \\
\hline Cloud cover $(\%)$ & & \\
0 & $1.61 \pm 0.63(30)$ & $3.45 \pm 1.14(38)$ \\
$10-30$ & $1.89 \pm 0.84(13)$ & $3.03 \pm 0.83(26)$ \\
$40-60$ & $1.83 \pm 0.91(16)$ & $3.06 \pm 0.99(16)$ \\
$70-90$ & $1.76 \pm 0.82(20)$ & $2.19 \pm 1.23(16)$ \\
100 & $1.73 \pm 0.80(29)$ & $1.76 \pm 1.05(34)$ \\
Rain & $0.34 \pm 0.25(8)$ & $0.43 \pm 0.20(10)$ \\
\hline
\end{tabular}

ences in the nighttime decreased gradually as the cloud cover increased to $>60 \%$.

Fig. 8 shows the relationship between wind speeds and calculated air temperature differences $(\Delta T a)$. The linear regression equation and data from the 11 representative sites were used to calculate the air temperature differences between the 0 and $100 \%$ vegetated areas. This analysis was based on observations of $<60 \%$ cloud cover. As shown in Fig. 8, there were few variations in the air temperature differences related to wind speed during the day. In contrast, air temperature differences decreased significantly as wind speed increased to $>3 \mathrm{~m} \mathrm{~s}^{-1}$ at the night, and greater air temperature differences were seen in moderate wind conditions.

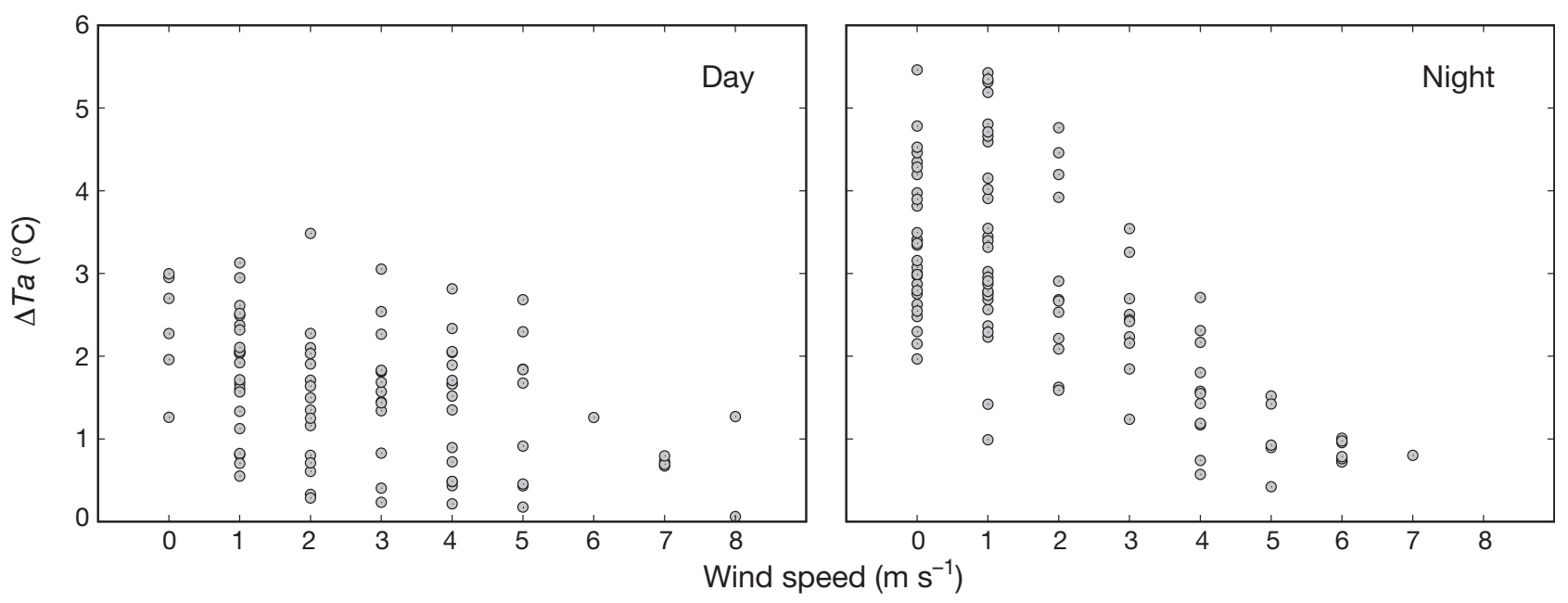

Fig. 8. Relationship between wind speeds and air temperature differences $(\Delta T a)$. Air temperature differences were calculated as the difference between the temperature in a $0 \%$ and that in a $100 \%$ vegetated area using a linear regression on data from the 11 representative sites, as described in Fig. 7. This analysis was based on observations of cloud cover of <60\%. Day: sunrise to sunset; night: sunset to sunrise 


\section{DISCUSSION}

\subsection{Causal factors in the enhancement of the intra-urban heat island}

\subsubsection{Vertical structures and radiative cooling}

We observed diurnal variations in the IUHI intensity throughout the year (Fig. 4). Oke (1987) concluded that the maximum UHI intensity occurs approximately 3 to $5 \mathrm{~h}$ after sunset. Several recent studies have found that the maximum intensity sometimes occurs at midnight (Runnalls \& Oke 2000, Chow \& Roth 2006) or shortly before sunrise (Erell \& Williamson 2007). The UHI intensity has even been found to be negative during the daytime (Chow \& Roth 2006, Erell \& Williamson 2007), which is then called a urban cool island. In the present study, however, IUHI intensities in summer increased to a greater extent during the day than at night. For example, during the day in summer under cloudless conditions, the air temperature difference between the built-up and the secondary woodland area was more than $4.5^{\circ} \mathrm{C}$, although the distance between observation sites was $<1 \mathrm{~km}$. At the same time, the temperature in the cropland was higher to some extent than that at the secondary woodland site, although it was lower than in the built-up area (Figs. 5 $\& 6)$. This is because broad-leaved trees at the woodland site blocked the incident solar radiation, causing air temperatures at that site to be less elevated during the day. On the other hand, there was little shade to block the incident solar radiation in the built-up area due to low-rise buildings and in the cropland area due to short vegetation. This led to an increase in the air temperatures at those sites compared to the woodland site. In other words, the maximum air temperature differences in summer were brought about by the presence of relatively low air temperatures observed at the secondary woodland sites. Although it seems that there is a correlation between daytime air temperature differences and solar radiation, this was not investigated accurately.

In contrast, IUHI intensities in spring, autumn, and winter were greater at night. This was because the radiative cooling rate is high from autumn to spring. In addition, the influence of the incident solar radiation during the day is smaller than in summer. Therefore, IUHI intensities in these seasons tended to be strong, especially at night. The surrounding rural areas, like the cropland area and the bare ground, are more exposed to the sky than the built-up area. This allows for a greater cooling of the cropland area and bare ground. At the same time, the decrease in temperature in the built-up area was lower because this area is surrounded by buildings, which regulate long-wave radia- tive heat loss (Oke 1981, 1982). As a result, there was a large air temperature difference between the built-up and the cropland area. In the present study, as shown in Fig. 5, the temperatures in the cropland area at night in these seasons were lower than the temperatures in the secondary woodland, due to a higher radiative cooling rate. Similarly, Spronken-Smith \& Oke (1998) found nocturnal maximum cooling in gardens and open grass parks, due to a high sky view factor and low thermal admittance, compared to parks with tree canopy cover, which have a daytime maximum cooling due to a combination of shade and evapotranspiration. Since the difference in radiative cooling rates between the builtup and the cropland area was particularly pronounced in winter, when the climatic conditions are suitable for radiative cooling, a maximum IUHI intensity of $6.9^{\circ} \mathrm{C}$ occurred during this season. In addition, the nocturnal IUHI intensity was weakest in summer because the atmospheric moisture content in summer was much higher than in other seasons, enhancing incoming long wave radiation from the sky.

\subsubsection{Anthropogenic heat}

Investigating the impact of anthropogenic heat on the urban climate in the Tokyo area, Ichinose et al. (1999) found that the anthropogenic heat generated from morning to evening was larger than that from evening to morning. In addition, whereas shortwave radiation was strong and the influence of anthropogenic heat was relatively small in summer, shortwave radiation was weak and the influence of anthropogenic heat was relatively large in winter. Sailor \& Lu (2004) also investigated anthropogenic heat in 6 large cities in the USA and presented similar results. In our study, daily maximum air temperature differences tended to be large during the day in summer and at night in the other seasons. This pattern of maximum air temperature differences was not consistent with the amount of anthropogenic heat presented in past studies (Ichinose et al. 1999, Sailor \& Lu 2004), which seems to indicate that the anthropogenic heat in our study area may not be a direct factor in the air temperature differences.

\subsubsection{Horizontal distribution of air temperatures}

As already described, maximum air temperature differences in our study area under calm and cloudless weather conditions ranged from 4.0 to $6.9^{\circ} \mathrm{C}$ during all seasons in the years studied. Our observations included various types of land covers that affect air temperature in different ways and at different times. Spronken- 
Smith \& Oke (1999) suggested that a vegetated area affects air temperatures in different ways, depending on the type of vegetation. In the present study, as mentioned above, maximum air temperature differences during the day occurred between the built-up and the secondary woodland area, especially in summer. However, the difference at night tended to occur between the built-up and the cropland area. As a result, temperature records showed the constant presence of an IUHI, although minimum air temperatures were observed in different land cover types. These results indicate that a city composed of various land cover types could form different kinds of UHIs at any time. In summary, the development of an IUHI is related to land cover features, and causal factors in the enhancement of the IUHI differ between day and night.

\subsection{Observed intra-urban heat island intensity compared to other cities}

Past studies (Oke 1973, 1981, 1982, Fukuoka 1983) have indicated that maximum UHI intensity was related to city size, as measured by its population. Oke (1973) reported that maximum UHI intensities were proportional to the logarithm of the population for many North American and European settlements. As suggested above, a maximum IUHI intensity of nearly $7^{\circ} \mathrm{C}$ was observed in our study area; the population is about 40000 in an area of approximately $10 \mathrm{~km}^{2}$. According to Oke (1973), a maximum UHI intensity of $7^{\circ} \mathrm{C}$ is equivalent to a population of approximately 30000 for a North American city and 300000 for a European city. Fukuoka (1983) conducted similar investigations in Japanese cities, and indicated a nonlinear relationship. According to Fukuoka's (1983) results, a maximum UHI intensity of $7^{\circ} \mathrm{C}$ in Japan is equivalent to a population of approximately 3000000 , and a population of 40000 is equivalent to a maximum UHI intensity of approximately $1.5^{\circ} \mathrm{C}$. Given the size of the city in our study area, the maximum IUHI intensity observed is significantly larger than that in other Japanese cities of similar size and corresponds to the results reported by Oke (1973) for North America.

Oke $(1981,1982)$ also noted that the size of a city, as measured by its population, could be a proxy for the sky view factor in city centers and anthropogenic heat. However, it seems that there was a low anthropogenic heat emission in our study area and a relatively large sky view factor in the built-up area due to low rise buildings that mainly consist of 2 to 3 story residences. This suggests that the sky view factor and anthropogenic heat are not the main factors causing maximum air temperature differences in the present study.
Oke (1973) and Fukuoka (1983) suggested that regional differences in the regression of maximum UHI intensity and city size were caused by differences in urban structures, urban functions, and climatic zone. Yamashita (1988) mentioned that a steep temperature gradient at the urban/rural boundary is typically not present due to the sprawl-like expansion of urban areas in Japan. However, our study area is clearly divided into an urban built-up and a rural vegetated area. Thus, observed IUHI intensities were large compared to other Japanese cities. This means that the impact on air temperature differences was significantly affected not only by the size of the city but also by differences in land cover types.

\subsection{Effect of land cover on ambient air temperatures}

Previous studies (Saito et al. 1991, Eliasson 1996a, Upmanis \& Chen 1999, Unger et al. 2001, Jonsson 2004, Bottyán et al. 2005, Hart \& Sailor 2009) reported the effects of land cover types on ambient air temperatures. In the present study, as shown in Figs. $5 \& 6$, the observed air temperatures varied significantly according to land cover types: air temperatures were higher in the built-up area and lower in the vegetated area. Based on these findings, we used 11 representative sites to examine the relationship between land cover and air temperature. As in previous studies (Saito et al. 1991, Unger et al. 2001, Bottyán et al. 2005), the observed air temperature decreased as the percentage of the vegetated area increased (Fig. 7). This means that the built-up areas are warming due to an increase in artificial land covers, and that the vegetated areas have moderating effects on ambient air temperatures. On average, the moderating effects were slightly stronger at night than during the day, although they varied slightly with the seasons and prevailing weather conditions. Therefore, it seems that the moderating effect produced by a higher cooling rate in the vegetated area at night could be larger than that produced by evapotranspiration and the blocking of incident solar radiation during the day. This is because the effects of different land cover types can easily connect with ambient air temperatures at night due to the stable boundary layer, which is dominated by the influence of diffusion rather than advection.

\subsection{Effect of cloud cover and wind speed on air temperature differences}

Since the difference in air temperature is influenced by meteorological variables, we also analyzed the relationship between air temperature differences and weather conditions (Table 2, Fig. 8). The effects of cloud 
cover and wind speed on the magnitude of the air temperature differences have been reported in previous studies (Unger 1996, Eliasson 1996b, Upmanis \& Chen 1999, Unger et al. 2001, Erell \& Williamson 2007). Unger (1996) and Unger et al. (2001) reported a negative relationship between cloud cover and air temperatures. As suggested in Table 2, the present study showed a similar result for nighttime measurements. This indicates that cloud cover influenced the moderating effect of the vegetated areas, especially at night, because the re-radiation from clouds diminished the amount of upward long-wave radiation emitted by the ground (Oke 1987, Morris et al. 2001). Similarly, although there was little difference in the magnitude of the moderating effects of vegetated areas during the day with respect to wind speeds, moderating effects at night decreased significantly as the wind speed increased to $>3 \mathrm{~m} \mathrm{~s}^{-1}$ (Fig. 8). This is due to the height of the surface boundary layer becoming lower or a stable layer developing under calm conditions at night, and the influence of diffusion being larger than that of advection, which enhances the air temperature differences. On the other hand, the influence of advection becomes larger than diffusion as the wind speed increases, which diminishes air temperature differences (Morris et al. 2001, Alonso et al. 2007). This result was in good agreement with those reported by Eliasson (1996b) and Erell \& Williamson (2007). Table 2 and Fig. 8 show strong radiative cooling under moderate wind conditions at night. According to these results, the magnitude of the moderating effects of vegetated areas varied due to weather conditions, especially at night.

\section{CONCLUSIONS}

Mobile traverses were used to measure air temperatures throughout the year to clarify the effect of different land cover types on ambient air temperatures. The main findings and conclusions are:

(1) In our study area, an IUHI was present throughout the year, and this IUHI showed diurnal and seasonal variations. Daily maximum intensities of the IUHI under calm and cloudless conditions ranged from 4.0 to $6.9^{\circ} \mathrm{C}$ during all seasons in the years studied. Previous studies suggested that the instensity of a UHI is determined by a city's size. In contrast, the IUHI intensity in our study area was high due to clear boundaries between different land cover types. The development of the IUHI was related to land cover features, and causal factors in the enhancement of the IUHI differ between day- and nighttime. The IUHI intensities tended to be high, particularly at night in winter, because of a high radiative cooling rate in the vegetated area and because the climatic conditions at night in winter were suitable for radiative cooling. Therefore, a maximum IUHI intensity of $6.9^{\circ} \mathrm{C}$ was observed during this time.

(2) The observed air temperatures were affected by ambient land cover types and decreased as the percentage of vegetated area around measurement sites increased. The effects of land cover on average yearround air temperatures were slightly stronger at night than during the day. On average, the moderating effect produced by a higher cooling rate in the vegetated area at night was greater than that produced by evapotranspiration and the interception of the incident solar radiation during the day. As a result, the IUHI was especially pronounced at night in winter.

(3) Although there were few differences in the magnitude of the moderating effects of the vegetated areas during the day with respect to cloud cover and wind speed, moderating effects at night decreased gradually as the cloud cover increased to $>60 \%$ or the wind speed increased to $>3 \mathrm{~m} \mathrm{~s}^{-1}$. This was because, at night, the moderating effects were produced by the high radiative cooling rate of the vegetated area, and this radiative cooling became particularly pronounced under calm and cloudless weather conditions.

We used land cover conditions representing the characteristics of the ground to explain air temperature differences. As shown in the results, there were strong relationships between the observed air temperatures and these land cover conditions, and, for the most part, we could elucidate the formation of air temperature differences in our study area using the land cover data. However, to explain the air temperature differences more precisely, spatial and seasonal sky view factor and soil moisture content data also need to be taken into account (Oke 1981, 1982, Jonsson 2004). Urban climate development should be studied by precise analysis of the effects of various parameters, in addition to land cover data, to quantify the roles of each of these factors.

Acknowledgements. This study was funded in part by a Waseda University Grant for Special Research Projects (2008B-244). The authors thank A. Kimura for useful suggestions and discussions.

\section{LITERATURE CITED}

Alonso MS, Fidalgo MR, Labajo JL (2007) The urban heat island in Salamanca (Spain) and its relationship to meteorological parameters. Clim Res 34:39-46

Bottyán Z, Kircsi A, Szegedi S, Unger J (2005) The relationship between built-up areas and the spatial development of the mean maximum urban heat island in Debrecen, Hungary. Int J Climatol 25:405-418

> Chow WTL, Roth M (2006) Temporal dynamics of the urban heat island of Singapore. Int J Climatol 26:2243-2260

> Eliasson I (1996a) Urban nocturnal temperatures, street geometry and land use. Atmos Environ 30:379-392 
Eliasson I (1996b) Intra-urban nocturnal temperature differences: a multivariate approach. Clim Res 7:21-30

Erell E, Williamson T (2007) Intra-urban differences in canopy layer air temperature at a mid-latitude city. Int J Climatol 27:1243-1255

Fukuoka Y (1983) Physical climatological discussion on causal factors of urban temperature. Mem Fac Integr Arts Sci Hiroshima Univ IV-8:157-168

Hart MA, Sailor DJ (2009) Quantifying the influence of landuse and surface characteristics on spatial variability in the urban heat island. Theor Appl Climatol 95:397-406

Ichinose T, Shimodozono K, Hanaki K (1999) Impact of anthropogenic heat on urban climate in Tokyo. Atmos Environ 33:3897-3909

Jonsson P (2004) Vegetation as an urban climate control in the subtropical city of Gaborone, Botswana. Int J Climatol 24: 1307-1322

Morris CJG, Simmonds I, Plummer N (2001) Quantification of the influences of wind and cloud on the nocturnal urban heat island of a large city. J Appl Meteorol 40:169-182

Oke TR (1973) City size and the urban heat island. Atmos Environ 7:769-779

$>$ Oke TR (1981) Canyon geometry and the nocturnal urban heat island: comparison of scale model and field observations. J Climatol 1:237-254

Oke TR (1982) The energetic basis of the urban heat island. Quart J R Met Soc 108:1-24

Oke TR (1987) Boundary layer climates. Routledge, London

Ooka R (2007) Recent development of assessment tools for urban climate and heat-island investigation especially based on experiences in Japan. Int J Climatol 27:1919-1930

Runnalls KE, Oke TR (2000) Dynamics and controls of the near-surface heat island of Vancouver, British Columbia.

Editorial responsibility: Helmut Mayer,

Freiburg, Germany
Phys Geogr 21:283-304

Sailor DJ, Lu L (2004) A top-down methodology for developing diurnal and seasonal anthropogenic heating profiles for urban areas. Atmos Environ 38:2737-2748

Saito I, Ishihara O, Katayama T (1991) Study of the effect of green areas on thermal environment in an urban area. Energy Build 15:493-498

Spronken-Smith RA, Oke TR (1998) The thermal regime of urban parks in two cities with different summer climate. Int J Remote Sens 19:2085-2104

> Spronken-Smith RA, Oke TR (1999) Scale modelling of nocturnal cooling in urban parks. Boundary-Layer Meteorol 93:287-312

> Unger J (1996) Heat island intensity with different meteorological conditions in a medium-sized town: Szeged, Hungary. Theor Appl Climatol 54:147-151

Unger J, Sümeghy Z, Zoboki J (2001) Temperature cross-section features in an urban area. Atmos Res 58:117-127

Upmanis H, Chen D (1999) Influence of geographical factors and meteorological variables on nocturnal urban-park temperature differences - a case study of summer 1995 in Göteborg, Sweden. Clim Res 13:125-139

Wilmers F (1991) Effects of vegetation on urban climate and buildings. Energy Build 15:507-514

Yamashita S (1988) Some studies of heat island in Japanwith special emphasis on the climatological aspects. Geogr Rev Jap Ser B 61:1-13

Yamashita S (1996) Detailed structure of heat island phenomena from moving observations from electric tram-cars in metropolitan Tokyo. Atmos Environ 30:429-435

Yokohari M, Brown RD, Kato Y, Yamamoto S (2001) The cooling effect of paddy fields on summertime air temperature in residential Tokyo, Japan. Landsc Urban Plan 53:17-27

Submitted: October 30, 2008; Accepted: April 6, 2009

Proofs received from author(s): June 4, 2009 